\title{
Método preliminar de detección de patógenos biológicos en cultivos de fresa por medio del procesamiento digital de imágenes
}

\section{Preliminary method of detection of biological pathogens in crops of Strawberry by means of digital image processing}

\begin{abstract}
Método de detecção preliminar de patógenos biológicos na cultura do morango por meio de processamento digital de imagens
\end{abstract}

\author{
Darío Amaya Hurtado ${ }^{1}$ \& Juan David Sandino Mora² \\ ${ }^{1}$ Ingeniero Electrónico, Especialista en Automatización de procesos industriales, Magíster \\ en teleinformática, Doctor en Ingeniería Mecánica. 2Estudiante de Ingeniería en Mecatrónica. \\ 1,2 Facultad de Ingeniería. Universidad Militar Nueva Granada. \\ Carrera 11 \# 101 - 80. Bogotá. Colombia \\ 1'dario.amaya@unimilitar.edu.co, ${ }^{2}$ u1801731@unimilitar.edu.co
}

\section{Resumen}

En la actualidad, muchos estudios enfocados en el reconocimiento de patógenos biológicos, a través de los frutos de cultivos de fresa son efectivas, sin embargo la adquisición de la imagen se realiza mediante métodos destructivos que implican arrancar los frutos de la planta. En la presente investigación se ha propuesto el desarrollo de un algoritmo que permita analizar los frutos de un cultivo de fresa (Fragaria $x$ ananassa), capaz de realizar una primera aproximación para distinguir Botrytis sp. y Sphaerotheca sp., usando un método no destructivo, es decir, recolectando las imágenes directamente del cultivo sin realizar intervención alguna por parte de los productores y/o investigadores. Las técnicas de procesamiento de imágenes implementadas incluyen suavizado, erosión, dilatación, detección de contornos, correspondencia de patrones, umbralización, entre otros. Los resultados obtenidos se visualizaron en una aplicación desarrollada en C\# usando la librería Emgu CV, mostrando al usuario un diagnóstico de la planta de estudio. Se concluye que es posible ofrecer un servicio de monitoreo preliminar de incidencia de patógenos usando este algoritmo, ahorrando tiempo para productores e investigadores que requieran una primera aproximación del estado del cultivo, con la posibilidad de ejecutarse tanto en computadores de escritorio y portátiles como en robots aéreos (drones) que posibilitan automatizar esta tarea.

Palabras clave: Botrytis sp., cámara digital, correspondencia de patrones, detección de contornos, Fragaria $x$ ananassa, Sphaerotheca $s p$. 


\section{Abstract}

Currently, many studies that have been focused on the recognition of biological pathogens, through the fruits of strawberry crops are effective, however the image acquisition is carried out by destructive methods that involve booting the fruits of the plant. In this research has been proposed the development of an algorithm that allows analyze the fruits of a cultivation of Strawberry (Fragaria $x$ ananassa), capable of performing a first approximation to distinguish Botrytis $s p$. and Sphaerotheca SP., using a non-destructive method, i.e., images are collected directly from cultivation without any intervention by the producers and/or researchers. The image's processing techniques that have been implemented include smoothing, erosion, dilation, detection of contours, patterns of correspondence, thresholding, among others. The results were visualized in an application developed in $\mathrm{C} \#$ using the library Emgu CV, which shows to the user a diagnosis of plant study. It was concluded that it is possible to offer a service of preliminary monitoring of incidence of pathogens using this algorithm, saving time for producers and researchers who require a first approximation of the crop, with the ability to be executed both on desktop computers and laptops as in aerial robots (drones) that makes it possible automate this task.

Keywords: Botrytis sp, digital camera, correspondence of patterns, detection of contours, Fragaria $x$ ananassa, Sphaerotheca sp.

\section{Resumo}

Atualmente, muitos estudos voltados ao reconhecimento de patógenos biológicos através dos frutos do morangueiro são eficazes; no entanto, a aquisição da imagem é realizada por meio de métodos destrutivos que envolvem o arranque dos frutos da planta. Nesta pesquisa foi proposto o desenvolvimento de um algoritmo que permita analisar os frutos de uma cultura de morango (Fragaria $x$ ananassa), de modo que seja capaz de realizar uma primeira aproximação para distinguir Botrytis sp. e Sphaerotheca sp., usando um método não destrutivo, ou seja, capturando imagens diretamente da cultura e sem envolvimento de produtores e/ou pesquisadores. As técnicas de processamento implementadas envolvem suavidade, erosão, dilatação, detecção de bordas, correspondência de padrões, umbralização, entre outros. Os resultados obtidos foram visualizados em um aplicativo desenvolvido em C\#, usando a biblioteca Emgu CV, mostrando ao usuário um estudo de diagnóstico da planta. Foi concluído que é possível oferecer um serviço de monitoramento preliminar de incidência de patógenos utilizando esse algoritmo, economizando tempo para os produtores e pesquisadores que precisam de uma primeira aproximação do estado da cultura, e com a capacidade de ser executado tanto em computadores como em robots aéreos (drones) que possibilitam automatizar esta tarefa.

Palavras-chave: Botrytis sp., Câmera digital, correspondência de padrões, detecção de bordas, Fragaria $x$ ananassa, Sphaerotheca sp.

\section{Introducción}

Muchas de las prácticas adoptadas en horticultura, específicamente en cultivos de fresa, son rigurosamente preventivas. Esto es realizado para garantizar que el producto ofrecido al mercado, se encuentre en las mejores condiciones nutricionales y sanitarias (Guadarrama Díaz, 2006), (Maas, 1998), (Flórez Faura \& Mora Cabeza, 2010), (Lallana \& Lallana, 2014). Cuando se manifiesta algún patógeno biológico relacionado con el cultivo, las acciones de control de enfermedades suelen ser prácticamente destructivas. En Lesur, Manual de Horticultura: una guía paso a paso, 2003 y Lesur, Manual de Fruticultura: una guía paso a paso, 2003, se muestra como en algunos casos, donde se detectan bacterias, hongos y virus en un cultivo, se dificulta la erradicación de éstos, si los síntomas en el tallo, hoja, folíolos y/o frutos, se encuentra en un estado muy avanzado. Cuando 
se presenta este tipo de situaciones es recomendable actuar rápido para preservar las camas del cultivo durante su ciclo de vida, por tanto es indispensable conocer el estado del cultivo y generar un diagnóstico adecuado antes de tomar esta clase de decisiones.

Los catálogos y textos relacionados con la identificación de enfermedades en cultivos de fresa, corresponden a variedades que se cultivan en Estados Unidos (Maas, 1998). En el caso colombiano aún no existen catálogos oficiales, que permitan identificar cada uno de los patógenos biológicos, a los que pueden estar expuestas las variedades de fresa que se cultivan en el país (Lexus, 2007). A pesar de que estas fuentes de información sean muy ilustrativas (Lallana \& Lallana, 2014), los síntomas que pueden presentarse en las camas de un cultivo de fresa, suelen ser difícilmente distinguibles para las personas que carezcan de contacto directo con él. Además, los análisis de laboratorio llevan un tiempo considerable y los diagnósticos muchas veces no resultan ser los más adecuados.

Las investigaciones enfocadas en la identificación y recopilación de información en los cultivos de fresa a través de su fisiología, mediante la adquisición de imágenes en sus frutos, han sido efectivos, siempre y cuando se implementen métodos directos cuya metodología implica arrancar los frutos de la planta en estudio, como se presentan en Du \& Sun, 2004, Lu, Ren, Zhang, \& Shen, 2010, Bock \& Nutter Jr, 2011, Jingwen \& Hong, 2012 y Schikora \& Schikora, 2014.

Independientemente de los algoritmos de visión de máquina ejecutados en estas investigaciones, se observa, que estas técnicas no resultan muy convenientes debido a que se consideran destructivas. Basado en esto, se propone en esta investigación validar un algoritmo que permita identificar enfermedades que pueden presentarse en plantas de fresa (Fragaria $x$ ananassa) del cultivar Albion usando procesamiento digital de imágenes. La metodología implementada evitará utilizar métodos directos o destructivos para la adquisición de datos. La identificación de las anomalías deberá hacerse usando un sistema de visión artificial en una interfaz gráfica de usuario (GUI), de forma rápida e intuitiva para el usuario final, que permita ofrecer una primera aproximación de monitoreo de incidencia de patógenos en las plantas de estudio.

\section{Materiales y Métodos}

Para el desarrollo de esta investigación, se realizó una toma de imágenes al cultivo de fresa de manera indirecta, las cuales fueron posteriormente procesadas diseñando una aplicación desarrollada en C\# usando la librería Emgu CV, utilizando métodos de detección de contornos, correspondencia de patrones, umbralización, suavizado, erosión, dilatación, entre otros. Los resultados permiten mostrar al usuario el diagnóstico de un posible patógeno al cual puede estar afectando la planta de estudio. En la Figura 1 se puede apreciar el esquema de los principales componentes de trabajo.

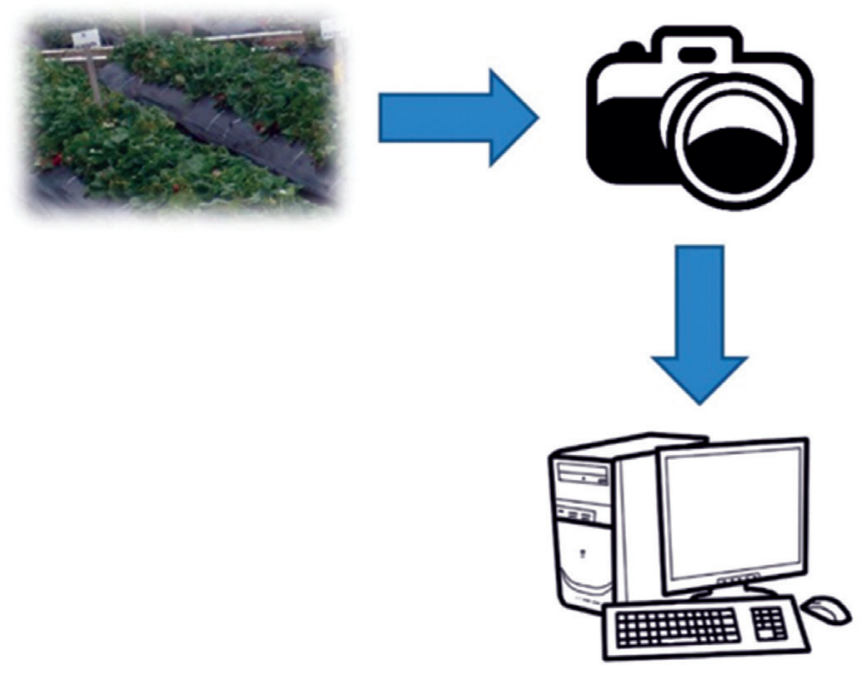

Figura 1. Representación de las condiciones de trabajo

Se toma como base experimental plantas de fresa del cultivar Albion, en el Campus Nueva Granada, de la Universidad Militar Nueva Granada, ubicado en el municipio de Cajicá, Cundinamarca, Colombia, bajo una temperatura promedio de $14^{\circ} \mathrm{C}$, a una altitud de 2.560 msnm y humedad relativa promedio del 
85.06\%. El área del cultivo en estudio fue de 403.2 $\mathrm{m}^{2}$, constituido por 9 camas elevadas de $13.5 \mathrm{~m}$ de largo por $0.7 \mathrm{~m}$ de ancho y la distancia de siembra entre las camas fue de $0.4 \mathrm{~m}$ (Figura 2).

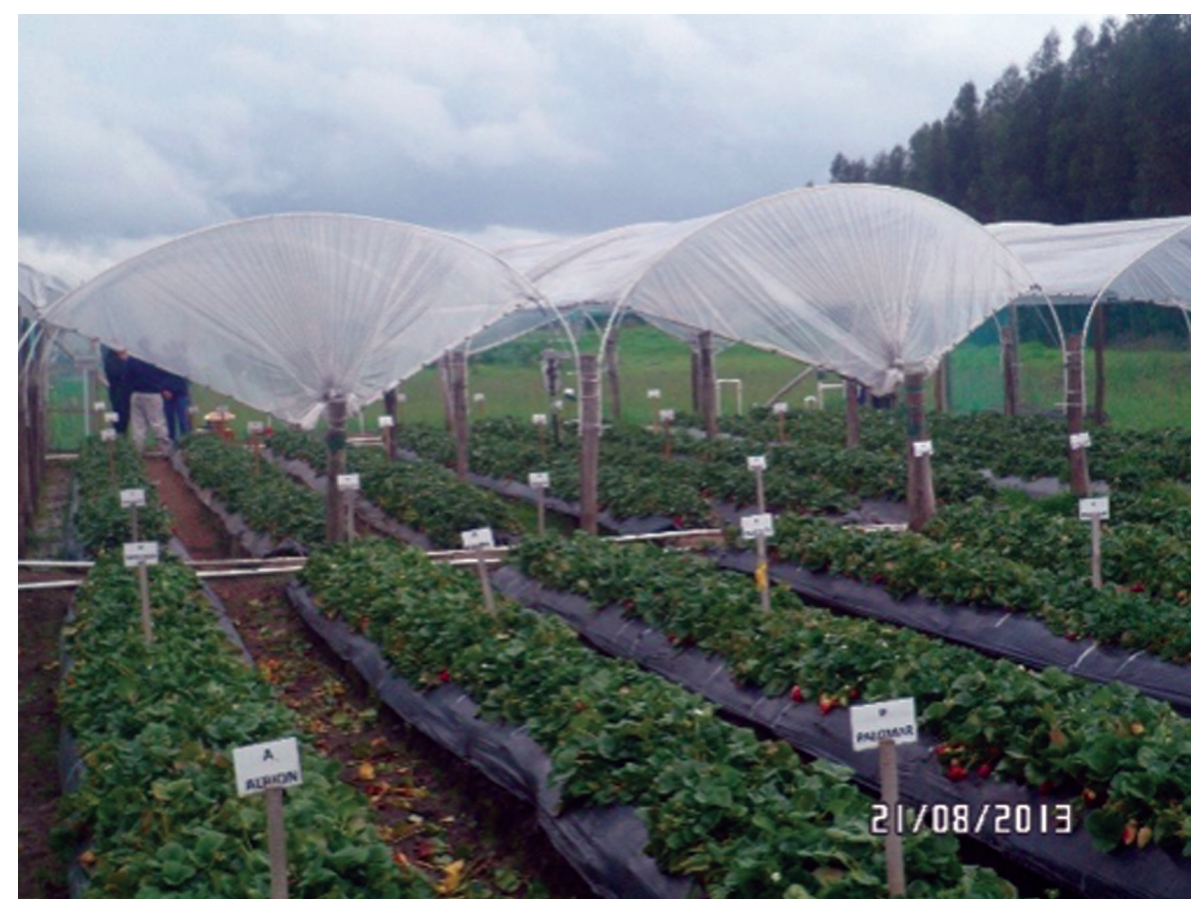

Figura 2. Vista general del cultivo de fresa del Campus Nueva Granada

Definido el espacio de trabajo, se obtienen las imágenes tomando las capturas directamente sobre el cultivo, evitando tener contacto directo con las plantas de las camas de fresa. La adquisición de las imágenes, se obtiene por medio de una cámara digital fotográfica, con especificaciones de resolución de $16 \mathrm{MP}$, ajustes de brillo y contraste automáticos, velocidad de captura de $250 \mathrm{~Hz}$ y formato de salida JPEG. Cada captura se realiza de forma manual, evitando así utilizar el zoom digital. Las imágenes fueron tomadas entre las 10:00a.m y 11:00a.m, bajo condiciones meteorológicas de cielo parcialmente nublado.

Al obtener una base de datos con imágenes que presentan diversas anomalías en el cultivo estudiado, se desarrolló un algoritmo que permite identificar dichas singularidades, el cual fue posteriormente ejecutado a través de una Interfaz Gráfica de Usuario (GUI) en un computador de escritorio bajo las siguientes especificaciones: procesador AMD Athlon II X245 (2 x 2.9GHz), memoria RAM de 4GB DDR2, tarjeta gráfica ATI Radeon
HD 4350 y sistema operativo Windows 8.1 Update (64bit). Con el fin de automatizar el reconocimiento de anomalías en plantas de fresa, el algoritmo propuesto tuvo la capacidad de seleccionar automáticamente la metodología apropiada para cada uno de los posibles diagnósticos que puedan presentarse en el monitoreo de incidencia.

\section{Resultados}

\section{Algoritmo de identificación propuesto}

En la Figura 3, se presenta el algoritmo propuesto para la identificación de patógenos en el cultivo de estudio. El algoritmo, tiene la capacidad de diferenciar, si la imagen a analizar, fue enfocada en los frutos de la planta. De darse esta situación, el algoritmo tendrá la capacidad de reconocer la existencia de Botrytis sp. y Sphaerotheca sp. De lo contrario el algoritmo aborta la metodología de diagnóstico manifestando al usuario que la imagen adquirida no se encuentra enfocando las camas de 
fresa. Una vez se identifique el tipo de estudio a llevar a cabo, fueron efectuadas diferentes técnicas de segmentación de imagen para identificar posibles anomalías en las plantas de estudio.

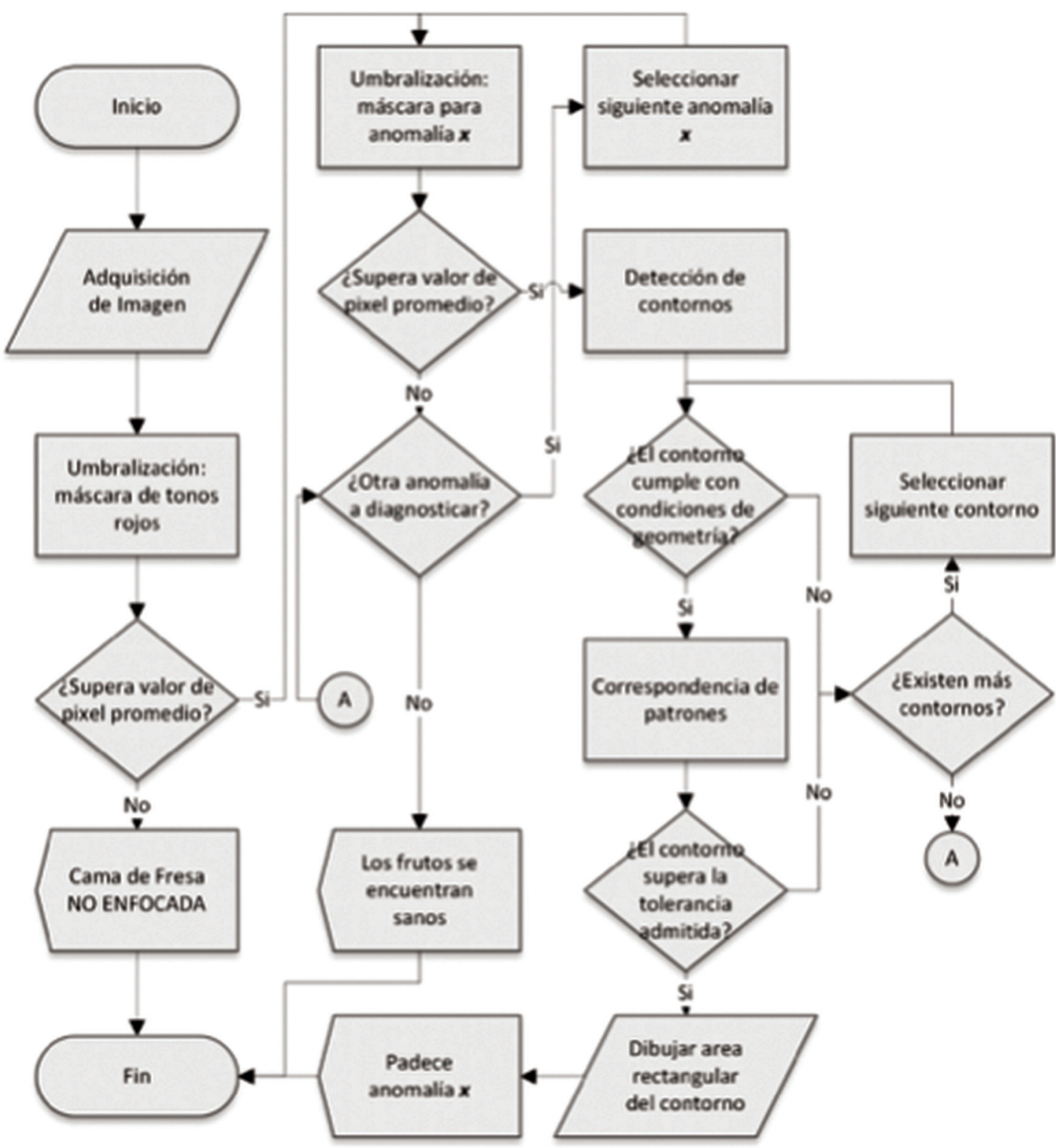

Figura 3. Diagrama de flujo general para detectar anomalías en frutos para plantas de fresa

Al cargar la imagen en la aplicación, se realizó una conversión de los datos contenidos en ella, desde el formato Red, Green, Blue (RGB) característico de las cámaras digitales, al formato Hue, Saturation, Value (HSV) a través del algoritmo propuesto por OpenCV - Miscellaneous Image Transformations, 2015, el cual mejora analíticamente la distinción de los colores contenidos en una imagen.
Luego se obtuvo una máscara digital principal con el fin de determinar si la imagen original fue enfocada en los frutos de la planta. Para obtener la máscara, se realiza una umbralización usando el método InRange(...), retornando una imagen binaria tomando como base la Ecuación 1, donde es la imagen de origen, es la imagen resultante, y a los rangos HSV inferior y superior respectivamente. 
$\operatorname{dst}(\mathrm{I})=\left\{\begin{array}{c}255 \rightarrow \text { lowerb }(\mathrm{I})_{0} \leq \operatorname{src}(\mathrm{I})_{0} \leq \text { upperb(I) } \\ 0 \rightarrow \text { de lo contrario }\end{array}\right.$

Con la imagen binaria y utilizando el método Get Average(...) (Ecuación 2, donde i es la imagen de origen y $\mathrm{I}$ el número de pixeles contenidas en $\mathrm{n}$ ), se obtuvo la media de los valores de todos los pixeles que conforman la máscara principal. Con dichos valores se determinaron los niveles de intensidad de tonos rojos para distinguir los frutos, por lo tanto, la imagen original fue considerada candidata a ser analizada si la media es superior a 6.0 , que equivale al $2.35 \%$ de intensidad.

$$
\operatorname{Avg}=\frac{\sum_{\mathrm{i}=0}^{\mathrm{n}} \operatorname{src}(\mathrm{I})_{0}}{\mathrm{n}}
$$

A las imágenes que superaron esta condición, les fue aplicado un filtro de suavizado, utilizando el método SmoothMedian(...) definido por la Ecuación 3, con el propósito de atenuar el ruido presente en la adquisición de la imagen, característico en las cámaras digitales.

$$
\mathrm{K}=\frac{1}{2 * \mathrm{ks}}\left[\begin{array}{cccccc}
1 & 1 & 1 & \cdots & 1 & 1 \\
& \vdots & & \ddots & \vdots \\
1 & 1 & 1 & \cdots & & 1
\end{array}\right]
$$

Donde es un valor impar, equivalente al tamaño de la apertura. Teniendo en cuenta que este filtro de suavizado reduce el área de los contornos obtenidos, se aplica el método Dilate(...) (Ecuación 4 ), el cual aumenta las regiones que contengan más brillo. Un ejemplo de la operación anterior se visualiza en la imagen superior derecha ilustrada en la Figura 4.

$$
\operatorname{dst}(x, y)=\max _{\left(x^{\prime}, y^{\prime}\right): \text { element }\left(x^{\prime}, y^{\prime}\right) \neq 0} \operatorname{src}\left(x+x^{\prime}, y+y^{\prime}\right)
$$

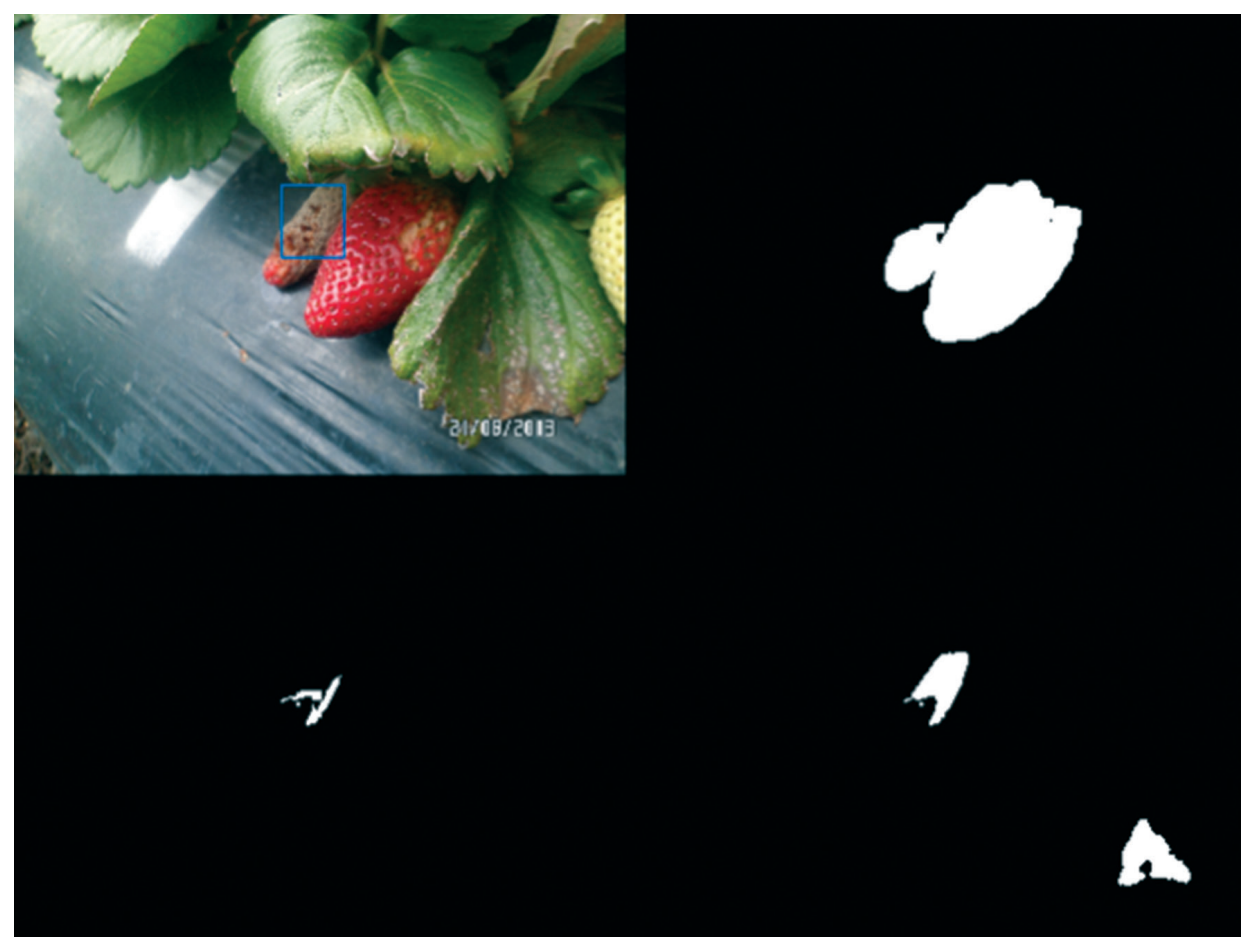

Figura 4. llustración de las operaciones principales del algoritmo propuesto. Imagen superior izquierda: imagen original para diagnosticar botrytis cinérea; imagen superior derecha: máscara principal de tonos rojos; imagen inferior derecha; mascara generada para detectar botrytis; imagen inferior izquierda; operación AND entre las 2 imágenes anteriores. 
Para realizar el diagnóstico del objeto de interés, se aplica a la imagen original, una operación de umbralización en formato HSV, a través del método InRange(...) (Ecuación 1), cuyos parámetros están predefinidos para cada una de las anomalías incluidas en este estudio. Con la imagen binaria resultante, se verifica la existencia de algún contorno usando el método GetAverage(...) (Ecuación 2). Si no se detecta ninguna región en la imagen binaria, se descarta la presencia de la anomalía en la imagen analizada. En la imagen inferior derecha de la Figura 4, se ilustra un ejemplo de la imagen retornada para evaluar Botrytis $s p$.

A la imagen resultante se le aplica la operación lógica AND (Ecuación 5), que determina si las regiones resaltadas de la anomalía, se encuentran incrustadas de las zonas de la máscara principal, descartando así resultados erróneos por contornos que pertenezcan a otros objetos.

$$
\operatorname{dst}(x, y)=\left\{\begin{array}{c}
255 \rightarrow \operatorname{src} 1(x, y)=\operatorname{src} 2(x, y) \wedge \operatorname{src} 1(x, y), \operatorname{src} 2(x, y) \neq 0 \\
0 \rightarrow \text { de lo contrario }
\end{array}\right.
$$

Donde es la imagen resultante, y equivalen a las imágenes de origen para efectuar la operación lógica $A N D$. Los resultados de esta operación se observan en la imagen inferior derecha de la Figura 4. Enseguida se discriminan los contornos exteriores de la imagen resultante, utilizando el método FindContours(...), de acuerdo con el algoritmo expuesto en (OpenCV - Structural Analysis and Shape Descriptors, 2015).

Con los contornos obtenidos se ejecutan métodos que permitan discriminar cada región por su tamaño y forma. Para ello cada uno de los contornos fueron analizados con el método ApproxPoly(...) usando el algoritmo de Ramer-Douglas-Peucker (Ramer, 1972) (Douglas \& Peucker, 1973) (Hershberger \& Snoeyink, 1992), generando nuevas regiones cuya forma se aproxima a la de un polígono ordinario. El objetivo de esta operación consistió en comparar los contornos generados con un patrón pre-definido con el método MatchShapes(...) definido por la Ecuación 6.

$$
I(A, B)=\sum_{i=1 . . .7}\left|\frac{1}{m_{i}^{A}}-\frac{1}{m_{i}^{B}}\right|
$$

\section{Donde}

$$
\begin{aligned}
& m_{i}^{A}=\operatorname{sign}\left(h_{i}^{A}\right) \cdot \log h_{i}^{A} \\
& m_{i}^{B}=\operatorname{sign}\left(h_{i}^{B}\right) \cdot \log h_{i}^{B}
\end{aligned}
$$

Los valores $\mathrm{A}$ y $\mathrm{B}$ corresponden a los objetos a comparar, y a los momentos de $\mathrm{Hu}$ de los objetos A y $B$ respectivamente. Los siete momentos utilizados para la correspondencia de patrones están definidos por (Hu, 1962). Los patrones pre-definidos son generados mediante la declaración de un vector de puntos tal y como se observa en la Figura 5.

\begin{tabular}{|r|r|r|r|r|}
\hline & 0 & 1 & 2 & 3 \\
\hline 0 & 0,0 & 1,0 & 2,0 & 3,0 \\
\hline 1 & 0,1 & & & 3,1 \\
\hline 2 & 0,2 & & & 3,2 \\
\hline 3 & 0,3 & & & 3,3 \\
\hline 4 & 0,4 & & & 3,4 \\
\hline 5 & 0,5 & & & 3,5 \\
\hline 6 & 0,6 & & & 3,6 \\
\hline 7 & 0,7 & & & 3,7 \\
\hline 8 & 0,8 & 1,8 & 2,8 & 3,8 \\
\hline
\end{tabular}

Figura 5. Patrón de ejemplo para un contorno de forma rectangular.

Fuente: Asano, Del Fierro, \& Grandeza , 2011.

El método devuelve un valor flotante indicando la relación entre el contorno de entrada y el patrón predefinido en un rango de 0.0 (ambas regiones coinciden) a 1.0 (no coinciden en lo absoluto). Finalmente se establece una tolerancia para el valor devuelto por el método para definir si el contorno será dibujado. El resultado final del diagnóstico se 
aprecia en la imagen superior izquierda de la Figura 4. Una vez se terminen de dibujar los contornos clasificados se publica el diagnóstico en la GUI.

\section{Diseño de la Interfaz Gráfica de Usuario (GUI)}

El diseño de la GUI (Figura 6) permite interactuar de manera dinámica la ejecución del algoritmo planteado para su uso en el usuario final.
Esta permite cargar imágenes y vídeos desde una ubicación en el equipo, cargar plantillas de demostración para interpretar de manera rápida el funcionamiento de la aplicación, una barra de herramientas visualizando controles de reproducción de vídeos y el tiempo invertido en el procesamiento del algoritmo, junto con caja de texto mostrando el diagnóstico del objeto de estudio. Los resultados se guardan generando una imagen visualizada en la GUI cuyo nombre corresponde al diagnóstico asignado por el algoritmo.

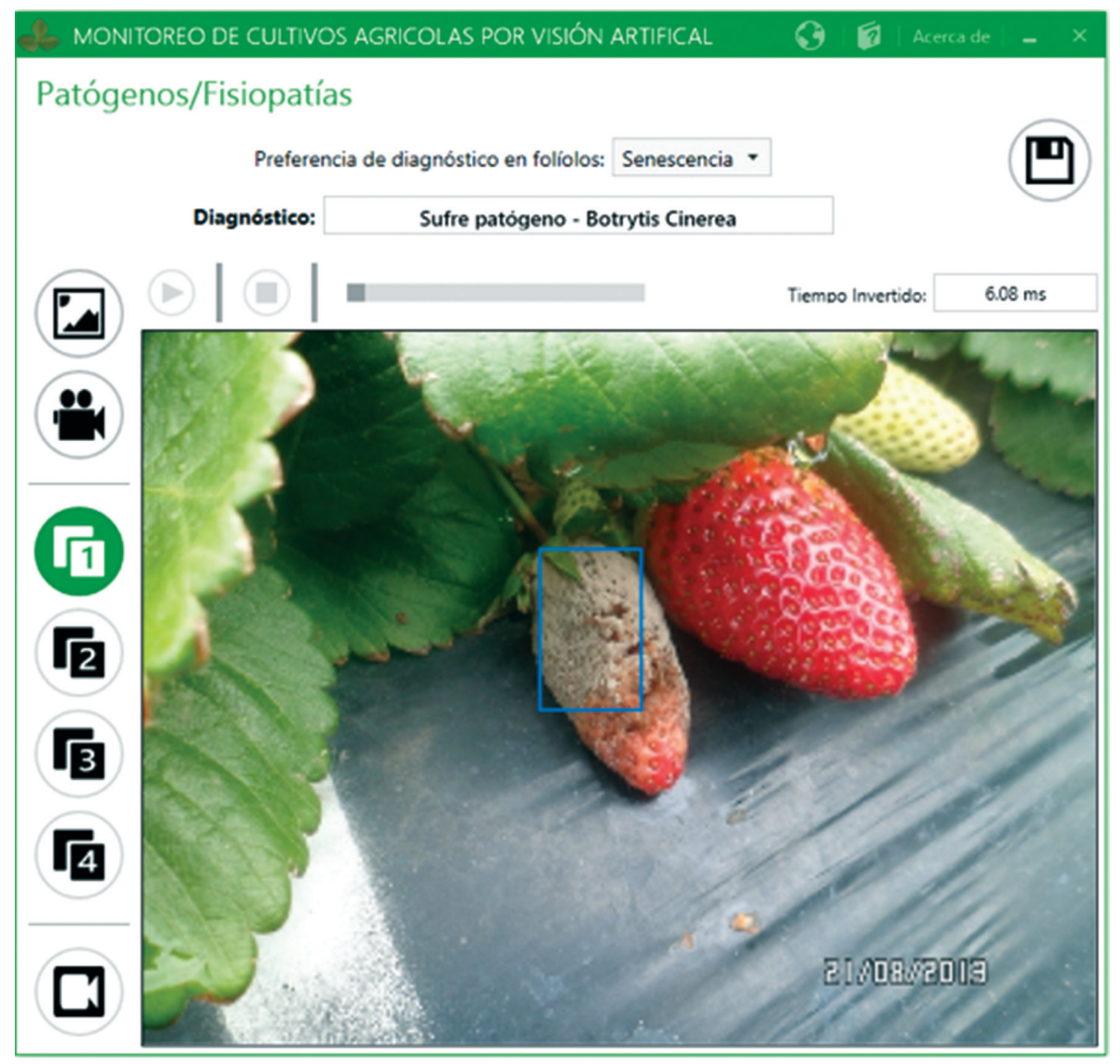

Figura 6. Ejecución del algoritmo en la GUI, entregando al usuario un diagnostico de Botrytis sp.

\section{Discusión}

Se realizaron pruebas de rendimiento de la aplicación utilizando el tiempo invertido en cada una de las pruebas (Figura 7). Dichas pruebas se clasificaron de acuerdo a los posibles diagnósticos que el algoritmo arroja al usuario (plantas enfermas, plantas sanas e imágenes no enfocadas en las camas del cultivo). 


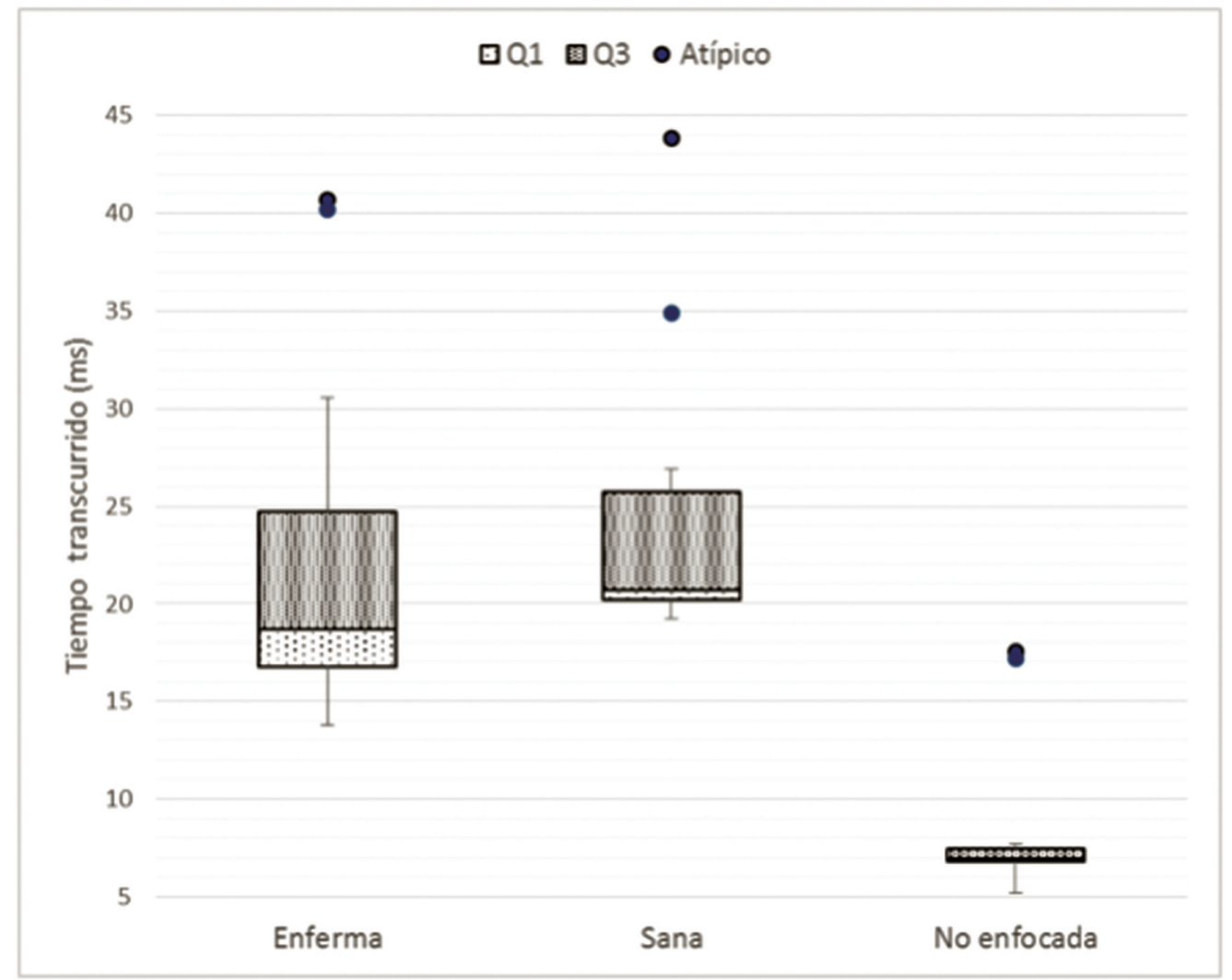

Figura 7. Representación del tiempo invertido por el algoritmo para arrojar cada uno de los posibles diagnósticos

La asimetría observada en la categoría de plantas enfermas (Botrytis sp. y Sphaerotheca sp.) corresponde al número variable de contornos que es capaz de detectar el algoritmo en cada captura fotográfica; en términos generales, el número de regiones es escaso para un fruto que padezca los primeros síntomas de una enfermedad, y viceversa. No obstante los valores del cuartil $1(17 \mathrm{~ms})$ y cuartil $3(24 \mathrm{~ms})$ evidencian que el rendimiento del algoritmo se adecua para reproducir vídeos a $60 \mathrm{~Hz}$ (33.33ms o 30 FPS) sin ninguna dificultad, y con suficiente estabilidad al obtener aprox. 2 ms de diferencia entre la mediana y el cuartil 1. Una situación similar ocurre al analizar plantas con frutos sanos, salvo que se observa un leve incremento en la magnitud de todos los cuartiles, a causa de que este diagnóstico es arrojado por descarte. En el caso contrario se situó la categoría de "imágenes no enfocadas en las camas del cultivo", cuya mediana fue de $7 \mathrm{~ms}$ y el rango intercuartílico no superó $1 \mathrm{~ms}$, puesto que, de acuerdo con el algoritmo de la Figura 3, se aborta la ejecución de métodos de segmentación de imagen si no se cumplen las condiciones de pre-procesado de imagen mencionadas con anterioridad. Finalmente los valores atípicos en las 3 categorías conciernen a registros altos de tiempos al ejecutar las primeras muestras (imágenes), debido a que los módulos del programa requieren de cargarse en la memoria del PC. El rendimiento en general es sobresaliente para imágenes con resoluciones bajas $(320 \times 240)$ y $(640 \times 480)$. Sin embargo en la reproducción de vídeos es evidente una caída notable de hasta 15 FPS para vídeos de $640 \times 480$. 
Con el fin de obtener la eficiencia de cada algoritmo para arrojar un diagnóstico acertado, se muestrearon un total de 15 imágenes obtenidas para cada patógeno de acuerdo con la Ecuación 7, donde corresponde al número de diagnósticos acertados y al número de diagnósticos errados. Los resultados obtenidos se muestran en la Figura 8.

Exactitud $=\frac{D A-D E}{D A} * 100$

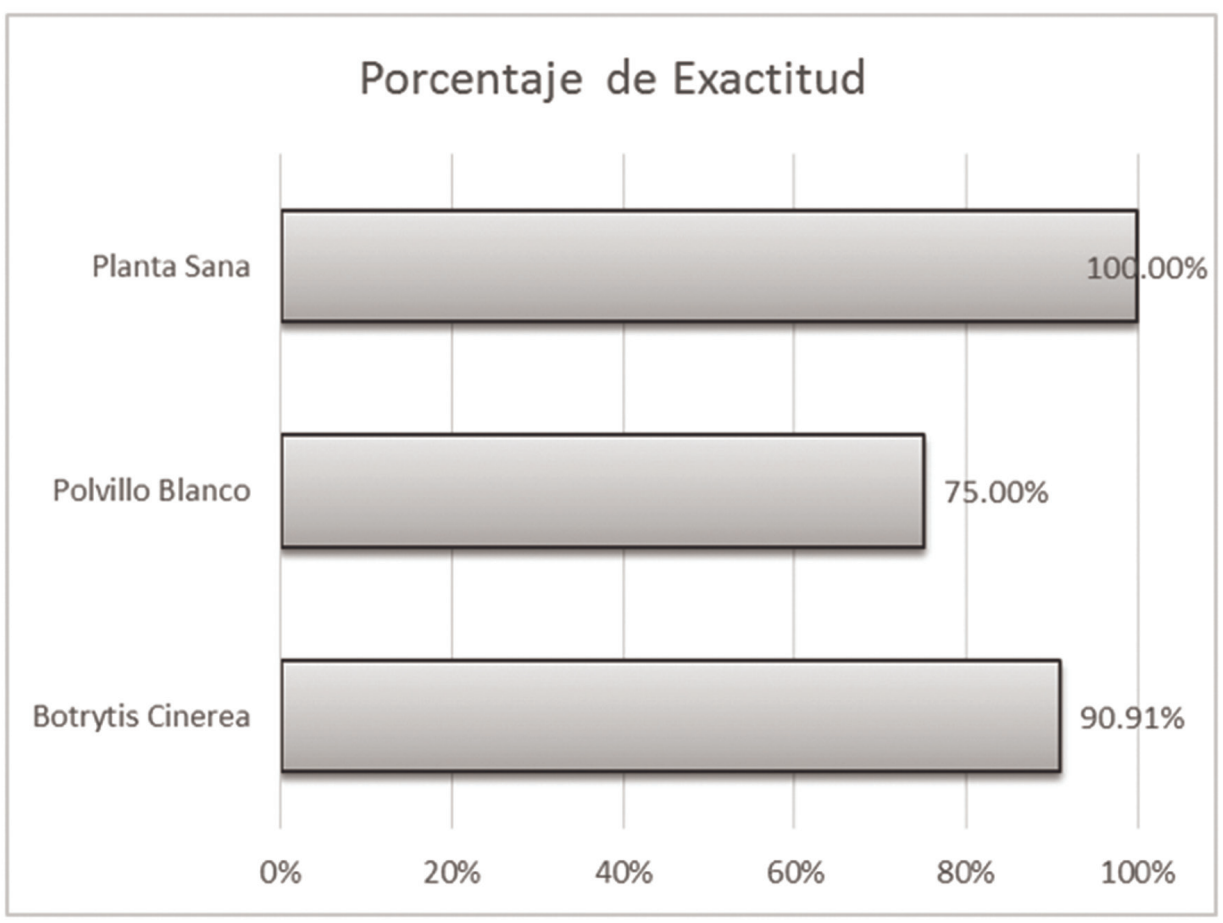

Figura 8. Eficiencia del algoritmo propuesto para cada uno de los patógenos biológicos analizados

El algoritmo fue específicamente planteado para analizar imágenes enfocadas a las plantas del cultivo de fresa, por lo que pueden generarse diagnósticos inadecuados a imágenes que no correspondan en lo absoluto con esta investigación. Por lo tanto se recomienda tener una herramienta de adquisición de imágenes de alta calidad, que permita distinguir con mayor claridad o nitidez los objetos entre sí.

El algoritmo propuesto y ejecutado en la GUI presentada en esta investigación visualiza diferentes ventajas a comparación de otros estudios: de acuerdo con (Sankaran, Mishra, Ehsani, \& Davis, 2010), los métodos recientes para la identificación de enfermedades en frutas, los cuales incluyen la espectroscopia en UV, espectroscopia en IR, imágenes por fluorescencia, cromatografía, imágenes hiperespectrales, entre otros, carecen de técnicas para suprimir la información del fondo en las imágenes obtenidas (disminuye la exactitud de los algoritmos usados), el alto costo de adquisición y mantenimiento de éstas técnicas, y la adquisición de imágenes no requiere de instalaciones y equipos aislados del cultivo, tal y como se evidencia en EIMasry, Wang, EISayed, \& Ngadi, 2007. Adicionalmente este estudio no implementa técnicas de química analítica costosas y lentas en validación de metodología (Vandendriessche, Keulemans, Geeraerd, Nicolai, \& Hertog, 2012), aunque se reitera que la aplicación permite una aproximación general y estas técnicas de validación no deben depreciarse en lo absoluto; aplicar dichas técnicas para monitoreos de incidencia en camas enteras de cultivos extensos representa un alto consumo de tiempo y recursos, caso contrario que otorga el algoritmo presentado en esta investigación. 
Los estudios mencionados anteriormente coinciden con el estudio actual, en que la optimización que requiere cada metodología para identificar anomalías en distintos cultivos agrícolas, no se obtiene usando algún método en particular y ésta debe adquirirse usando técnicas adicionales, como la ejecución de aplicaciones especializadas en el procesamiento de imágenes, aplicación de redes neuronales, algoritmos genéticos y/o técnicas de optimización (Huang, 2007, Camargo \& Smith, 2009). Finalmente se propone para futuras investigaciones la exportación de este tipo de aplicaciones a la nube virtual y a diferentes plataformas móviles para mejorar la portabilidad de esta herramienta de diagnóstico y así efectuar monitoreos de incidencia, dadas las tendencias actuales del mercado de software.

\section{Conclusiones}

Se propuso, ejecutó y validó un algoritmo robusto, preciso y exacto, para efectuar diagnósticos de Botrytis sp. y Sphaerotheca sp. en plantas de fresa del cultivar Albion a través de sus frutos usando procesamiento digital de imágenes. La ejecución de la aplicación respondió a niveles de rendimiento sobresalientes, aplicando siempre una metodología no destructiva en la adquisición de datos.

El algoritmo propuesto y ejecutado en la aplicación de usuario final (GUI), se considera una buena herramienta para biólogos, tecnólogos en horticultura y productores, que requieran una primera aproximación de monitoreo de incidencia de anomalías en las plantas de fresa, a bajo costo de ejecución y sin costos de mantenimiento.

El trabajo realizado permite efectuar futuras investigaciones para diagnosticar patógenos bajo una metodología similar, teniendo en cuenta que las herramientas de adquisición de imágenes pueden ser completamente compatibles con drones, cámaras web, diferentes cámaras digitales, tanto en cultivos de cielo abierto como aquellos cultivados bajo invernadero.

\section{Agradecimientos}

Los autores agradecen a: La Universidad Militar Nueva Granada por financiar este proyecto de iniciación científica (PIC ING - 1584) y al Biólogo Carlos Mario Grijalba Rátiva cM.Sc., por sus conocimientos y experiencia proporcionados en Horticultura, los cuales facilitaron el desarrollo de esta investigación y por los permisos concedidos para intervenir directamente en el cultivo de fresa del Campus Nueva Granada.

\section{Literatura citada}

1. Asano, A., Del Fierro, R., \& Grandeza, A. J. (2011). Determining the Stages of Malaria under Plasmodium Falciparum through Image Processing using EMGU Computer Vision. Philippines: Ateneo de Davao University.

2. Bock, C., \& Nutter Jr, F. (2011). Detection and measurement of plant disease symptoms using visible-wavelenght photography and image analysis. CAB Reviews Perspectives. Agriculture Veterinary Science Nutrition and Natural Resources, 74-87.

3. Camargo, A., \& Smith, J. (2009). An image-processing based algorithm to automatically identify plant disease visual symptoms. Biosystems Engineering, 102(1), 9-21. doi:10.1016/j.biosystemseng.2008.09.030

4. Douglas, D., \& Peucker, T. (1973). Algorithms for the reduction of the number of points required to represent a digitized line or its caricature. Cartographica: The International Journal for Geographic Information and Geovisualization, 10(2), 112-122. doi:10.3138/FM576770-U75U-7727

5. Du, C.-J., \& Sun, D.-W. (2004). Recent developments in the applications of image processing techniques for food quality evaluation. Trends in Food Science \& Technology, 15(5), 230 - 249. doi:http://dx.doi.org/10.1016/j. tifs.2003.10.006

6. EIMasry, G., Wang, N., EISayed, A., \& Ngadi, M. (2007). Hyperspectral imaging for nondestructive determination of some quality attributes for strawberry. Journal of Food Engineering, 81(1), 98-107. doi:10.1016/j.jfoodeng.2006.10.016

7. Flórez Faura, R., \& Mora Cabeza, R. A. (2010). Fresa (fragaria $x$ ananassa Duch.) producción y manejo poscosecha. Bogotá, Colombia: Editorial Universidad Nacional de Colombia.

8. Guadarrama Díaz, S. O. (2006). Guía Técnica para el Cultivo de Fresa. ICAMEX, San Antonio, México. Recuperado de http://portal2.edomex.gob.mx/icamex/investigacion_publicaciones/horticola/fresa/groups/public/ documents/edomex_archivo/icamex_arch_cultfresa.pdf

9. Hershberger, J., \& Snoeyink, J. (1992). Speeding Up the Douglas-Peucker Line-Simplification Algorithm. 16. Recuperado de http://www.cs.ubc.ca/cgi-bin/tr/1992/TR-92-07 
10. Hu, M. (1962). Visual Pattern Recognition by Moment Invariants. IRE Transactions on Information Theory, 8(2), 179-187.

11. Huang, K.-Y. (2007). Application of artificial neural network for detecting Phalaenopsis seedling diseases using color and texture features. Computers and Electronics in Agriculture, 57(1), 3-11. doi:57

12. Jingwen, W., \& Hong, L. (2012). Measurement and analysis of plant leaf area based on image processing. Information Technology in Medicine and Education (ITME), 2, págs. 1070-1074. doi:10.1109/ITiME.2012.6291485

13. Lallana, V. H., \& Lallana, M. (2014). Manual de Prácticas de Fisiología Vegetal. Córdoba, Argentina: Eduner. Recuperado, de http://www.eduner.uner.edu.ar/libro/96/ manual-de-practicas-de-fisiologia-vegetal

14. Lesur, L. (2003). Manual de Fruticultura: una guía paso a paso. Colombia: Editorial Trillas. Recuperado de http://www.libreriadelau.com/manual-de-fruticultura-una-guia-paso-a-paso-agropecuario-1.html\#. VTAsZfmG8 w

15. Lesur, L. (2003). Manual de Horticultura: una guía paso a paso. Colombia: Editorial Trillas. Recuperado de http:// www.luislesur.com/producto.php?idproducto $=7$

16. Lexus. (2007). Biblioteca de la Agricultura (Vol. II). Idea Books S.A. Recuperado de http://todoenciclopedias. com/idea.htm

17. Lu, C., Ren, H., Zhang, Y., \& Shen, Y. (2010). Leaf Area Measurement Based on Image Processing. Measuring Technology and Mechatronics Automation (ICMTMA), 2, págs. 580-582. doi:10.1109/ICMTMA.2010.141

18. Maas, J. L. (1998). Compendium of Strawberry diseases (2 ed.). (A. P. Society, Ed.) St. Paul, MN, Estados Unidos. Recuperado de http://www.apsnet.org/apsstore/shopapspress/Pages/41949.aspx

19. OpenCV - Miscellaneous Image Transformations. (2015). Miscellaneous Image Transformations OpenCV 2.4.10.0 documentation. Recuperado de http://docs.opencv.org/2.4.10/modules/imgproc/doc/ miscellaneous_transformations.html?highlight=hsv
20. OpenCV - Structural Analysis and Shape Descriptors. (2015). Structural Analysis and Shape Descriptors - OpenCV 2.4.11.0 documentation. Recuperado de http://docs.opencv.org/modules/imgproc/doc/structural_analysis_and_shape_descriptors.html

21. Pertot, I., Kuflik, T., Gordon, I., Freeman, S., \& Elad, Y. (2012). Identificator: A web-based tool for visual plant disease identification, a proof of concept with a case study on strawberry. Computers and Electronics in Agriculture, 84, 144-154. doi:10.1016/j.compag.2012.02.014

22. Ramer, U. (1972). An iterative procedure for the polygonal approximation of plane curves. Computer Graphics and Image Processing, 1(3), 244 - 256. doi:http://dx.doi. org/10.1016/S0146-664X(72)80017-0

23. Sankaran, S., Mishra, A., Ehsani, R., \& Davis, C. (2010). A review of advanced techniques for detecting plant diseases. Computers and Electronics in Agriculture, 72. doi:10.1016/j.compag.2010.02.007

24. Schikora, M., \& Schikora, A. (2014). Image-based Analysis to Study Plant Infection with Human Pathogens. Computational and Structural Biotechnology Journal, 12(20-21), 1-6. doi:10.1016/j.csbj.2014.09.010

25. Vandendriessche, T., Keulemans, J., Geeraerd, A., Nicolai, B., \& Hertog, M. (2012). Evaluation of fast volatile analysis for detection of Botrytis cinerea infections in strawberry. Food Microbiology, 32(2), 406-414. doi:10.1016/j.fm.2012.08.002

\section{Conflicto de Intereses}

Los autores declaran no tener ningún conflicto de intereses 